\title{
A Report of Marchantia polymorpha L., After a Forest Fire
}

\author{
by M. V. S. Raju, T. A. Steeves and J. D. Caponetti*, \\ University of Saskatchewan, Saskatoon.
}

Marchantia polymorpha L., one of the best known liverworts, is a thalloid terrestrial plant often found in moist places. The thick dorsiventral thallus, which is the gametophyte, has scales and rhizoids on its ventral surface. The rhizoids, although they are absorbing organs, do not represent true roots (Fig. 1). On the dorsal surface, the thallus produces two kinds of organs, the gametophores and the gemmae-cups (Figs. 1, 2). The thallus bears either male gametophores (antheridiophores) producing antheridia or female gametophores (archegoniophores) producing archegonia (Figs. 1, 2). The archegonium encloses an egg, which on fertilization by the sperm produced by the antheridium develops into $a$ complex structure, the sporophyte (Fig. 4). The sporophyte produces numerous spores and also elongated, hygroscopic, thread-like structures called elaters (Fig. 5). The spores are liberated to the exterior by the dehiscence of the sporophyte wall and are disseminated by the twisting of the elaters (Fig. 5). They ultimately develop into thalloid plants under favorable conditions.

The gemmae-cups are found on the dorsal surface in the mid-rib resion of both male and female thalli (Figs. 1, 2). They enclose a number of flat, dumb-bell shaped structures called gemmae which are able to develop into new gametophytes (Fig. 3 ). A gemma from a male plant is known to develop into a male adult thallus bearing antheridiophores and one from a female plant producces a thallus bearing archegoniophores.

During a visit to the boreal forest in northern Saskatchewan last summer (July, 1962), several burnt forest areas were observed. We had an opportunity to get into an area of recently burnt forest on the La Ronge Highway, about 77 miles north of Waskesiu Lake. Interestingly enough, we observed $M$. polymorpha growing in isolated patches on moist bumt soil (Fig. 6). In fact, it was one of the most conspicuous plants. Both antheridiophores and archegoniophores were found in every clump (Fig. 6). This occurrence of a liverwort in such abundance and its apparent absence from adjacent areas, made us curious to know the conditions that favored the pioneering invasion of burnt soil by $M$. polymorpha.

An actual fire in a forest produces enormous heat, reducing the vegetation to ashes, including the undergrowth. The degree of destruction of the vegetation has been reported to be dependent on the type of fire, i.e., ground fire, crown fire, etc. (Daub. enmire, 1959). Furthermore, the intense heat associated with a fire is known to destroy the viability of seeds and spores of many plants. The subterranean organs of perennials and of deep rooted plants often are not affected by it. The buried seeds and spores of plants also do normally escape fire injury. Moreover, in certain instances, the fire helps to crack open coniferous cones and consequently the seeds are liberated. The bare ground, after the destruction of vegetation by fire, may also result in the removal of competition that existed before fire. The exposure of burnt ground to insolation and removal of competition may favor the germination of seeds and spores under favorable moisture conditions and also stimulate the growth of some subterranean organs.

M. polymorpha is cosmopolitan in distribution, occurring under diverse environmental conditions (Schuster, 1957). Often, this and other liverworts have been recognized as ecological indicators of particular microenvironments. The occurrence of $M$. polymorpha in burnt deciduous and coniferous forests has been reported from North America and Europe. The exact conditions under which this liverwort invades and grows on burnt soil have so far not been deter-

\footnotetext{
* University of Tennessee, Knoxville, Tennessee, U.S.A.
} 


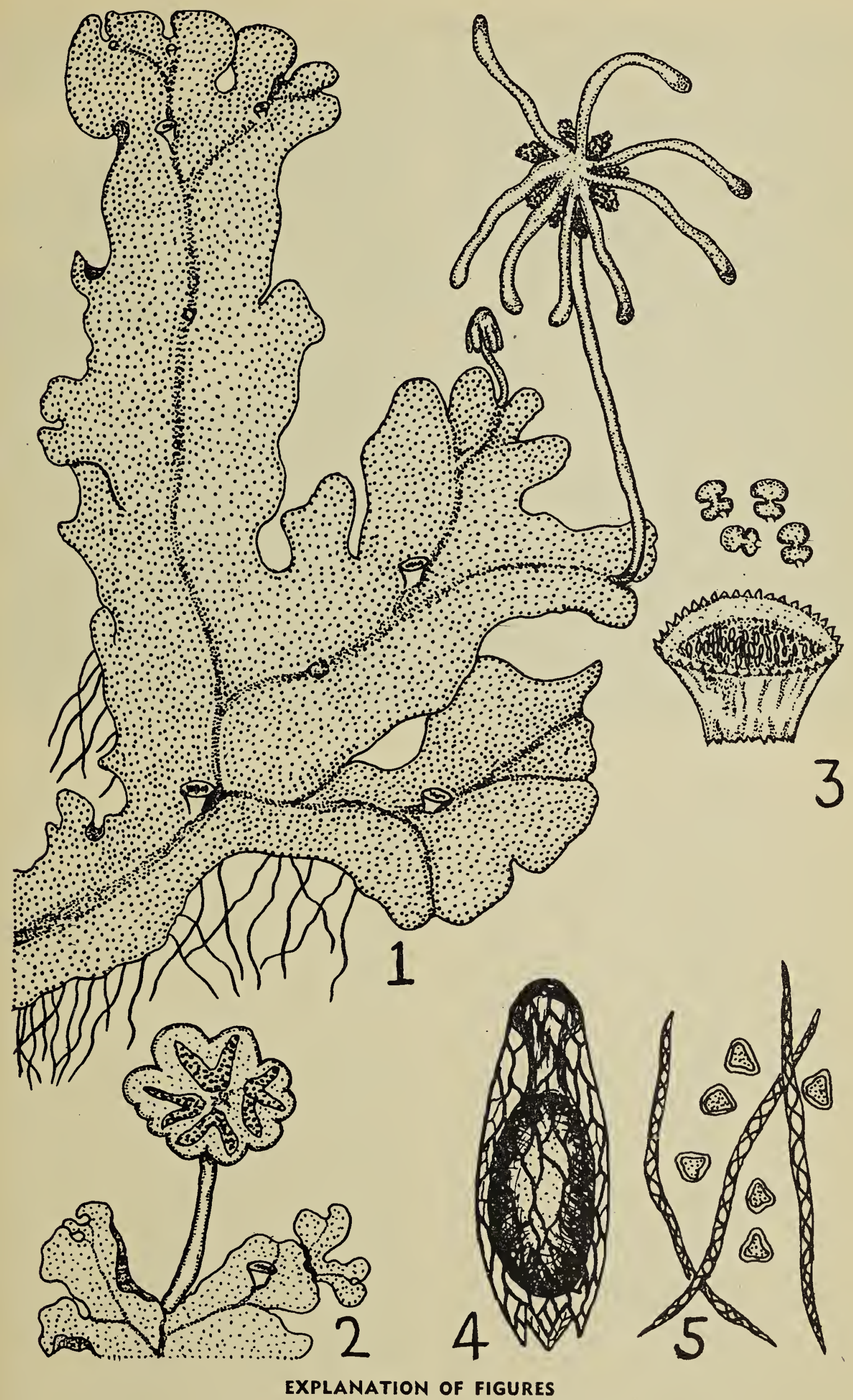

Fig. 1. Thallus shows gemmae-cups, archegoniophores and rhizoids, $X 3$.

Fig. 2. A portion of a thallus with gemmae-cups and antheridiophore, $\times 3$.

Fig. 3. A detached gemmae-cup with gemmae in it. Four free gemmae are shown above the Fig. 4. An entire sporophyte, $\times 15$

Fig. 5. A few elaters and spores, $\dot{X} 50$ 


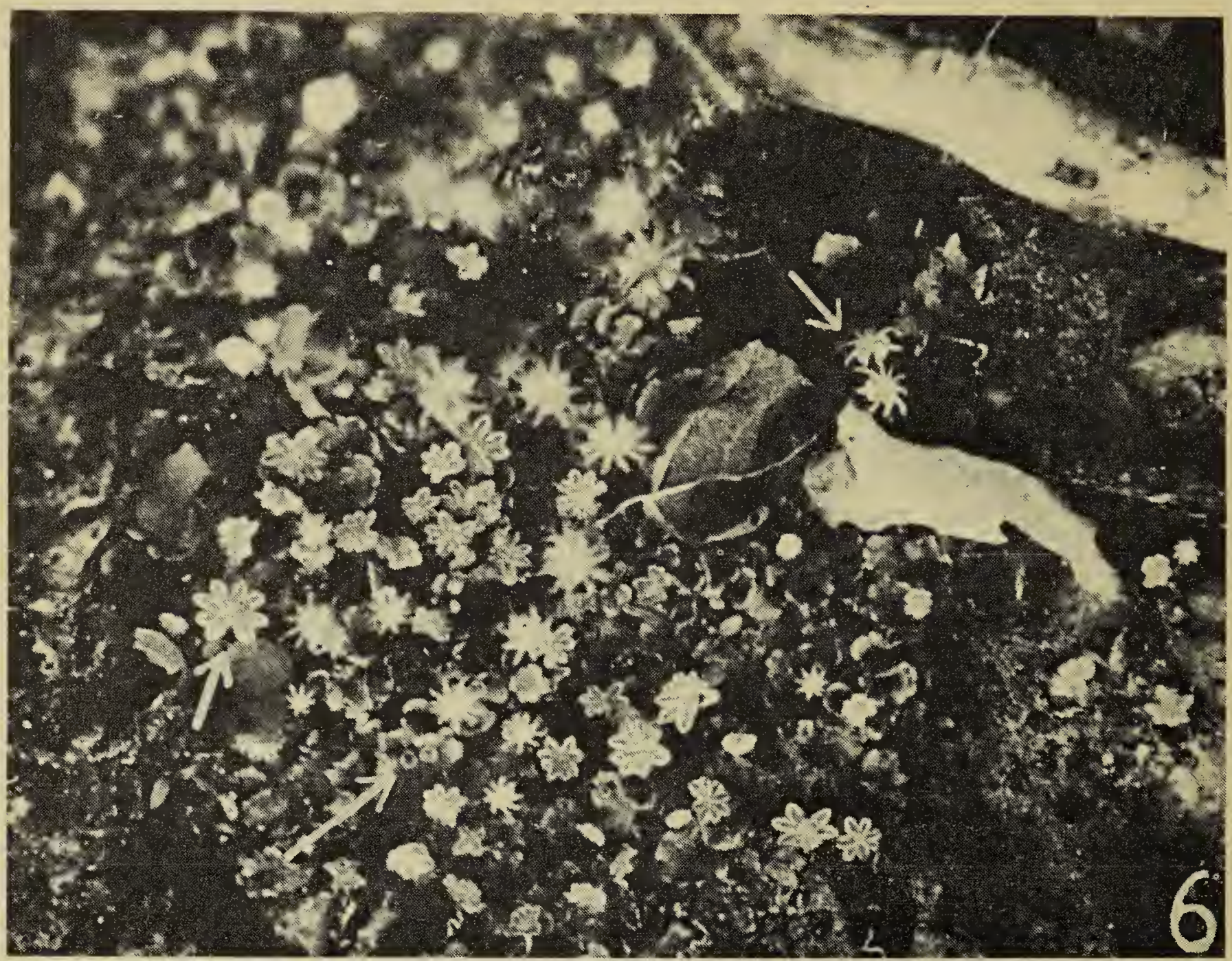

Fig. 6. Photograph of the liverwort in the burnt area. Note the gametophores and gemmaecups indicated by arrows. $\times 1 / 3$.

mined. Considerable work has, however, been done on $M$. polymorpha to find proper requirements for its normal grow th under laboratory and greenhouse conditions. Experimental results reported in published works aid in an appraisal of the possible conditions that may have favored not only the pioneering invasion by this liverwort but also its subsequent luxuriant growth on burnt soil. The sudden appearance of $M$. polymorpha on freshly burnt soil might be explained in two ways. Firstly, it may have come from elsewhere and established itself on burnt ground. If so, the spores, which are very light, must have been carried by wind or other' means from a considerable distance. The apparent absence of the liverwort in areas surrounding the burnt region and the absence of extraordinary dissemination mechanisms for favorable migration from great distances seem to suggest that spores did not come from elsewhere. The possibility of its survival in the vegetative state is remote for, in a laboratory experiment, it has been demonstrated that the thallus survived a temperature of $44.9^{\circ} \mathrm{C}$ and it died at $46.4^{\circ} \mathrm{C}$
(Schuster, 1957). In view of this, it seems more likely that spores, which are more resistant to adverse conditions than the vegetative thallus, were already present in the soil and escaped fire damage and germinated in profusion immediately after fire. However, detailed investigations would be needed to establish this fact.

It is known that fire brings about considerable decrease in organic compourds and mineral salts (Daubenmire, 1959). This change limits the growth of many plants considerably except those that can grow well under low salt concentrations in the soil. One such plant is $M$. polymorpha, which, according to experiments, is known to grow well in low salt concentrations (Voth, 1941, 1943). In the open burn forest, the thalli of this liverwort had produced a large number of gametophores. The production of gametophores has been shown experimentally in the laboratory to be influenced by daylength. The liverwort, if subjected to 17-18 hours of daylight per 24-hour cycle, produced gametophores extensively and relatively few gemmaecups. Under 8-9 hours of daylight, 
however, very few gametophores were formed and a large number of gemmae-cups appearea (Voth and Hammer, 1940). The production of gametophores is also known to be under the influence of concentration of salts. In about $0.2 \%$ concentration of salts in the substrate the thallus formed gametophores. In a similar experiment, $0.85 \%$ salts inhibited their development and a large number of gemmae-cups were produced instead (Schuster, 1957).

It thus seems possible that illumination and salt concentration, together with available moisture, could form essential requirements for the development of $M$. polymorpha on burnt ground. In nature, the level of concentration of salts in burnt ground is reported to be reduced considerably and natural illumination is also increased, particularly in summer (more than 16 hours per 24hour cycle) resulting in great vigor not only in the growth of vegetative thallus but also in the production of gametophores. Furthermore, the removal of competition occasioned by fire is also an important factor which may result in the conditions that favour the pioneering invasion by plants. Although more work needs to be done in this direction, it can be concluded that forest fire brings about considerable changes in the environment which favour the development of a few plants in early stages of plant succession. Among these few plants, Marchantia polymorpha is one.

\section{LITERATURE CITED}

Daubenmire, R. F. 1959. Plants and Environment. John Wiley \& Sons, U.S.A.

Schuster, R. M. 1957. Boreal Hepaticae, a Manual of the Liverworts of Minnesota and Adjacent Regions, II. Ecology. Amer. Midl. Nat. 57:203-299.

Voth, P. D. 1941. Gemmae cup production in Marchantia polymorpha and its response to calcium deficiency and supply of other rutrients. Bot.. Gaz. 103: 310-325.

Voth, P. D. 1943. Effects of nutrient-solution concentration on the growth of Marchantia polymorpha. Bot. Gaz. 103: 310-325.

Voth, P. D. and Hamner K. 1940. Response of Marchantia polymorpha to nutrient supply and photoperiod. Bot. Gaz. 102: 169-205.

\section{Plants of the Dry Sunny Slopes}

\section{by K. F. Best, Swift Current}

The rockcresses belong to the mustard family (Brassicaceae). Some refer to this family as Cruciferae, from the Latin crux, cross, and fero, bear, referring to the cross-like arrangement of the petals-a very marked characteristic of this family. These plants, even if not in flower, can often be recognized by the pungent or acrid taste of leaf and stem.

In the rockcress genus (Arabis, from Arabia), flowers are white, pink or purple, or rarely yellowish, and have the distinctive family character of four separate sepals, four sepate petals and six stamens, two of which are shorter than the others. The pistils mature into long, narrow, flattened pods with numerous seeds usually in two rows. Leaves are entire or toothed, stem leaves alternate, almost always stalkless and frequently with clasping bases. Usually there is a fairly dense cluster (rosette) of stalked leaves at the base of the stem.

The rockcresses are generally considered as of low forage value, but under some conditions, especially on overgrazed or depleted ranges, may be readily taken if succulent.

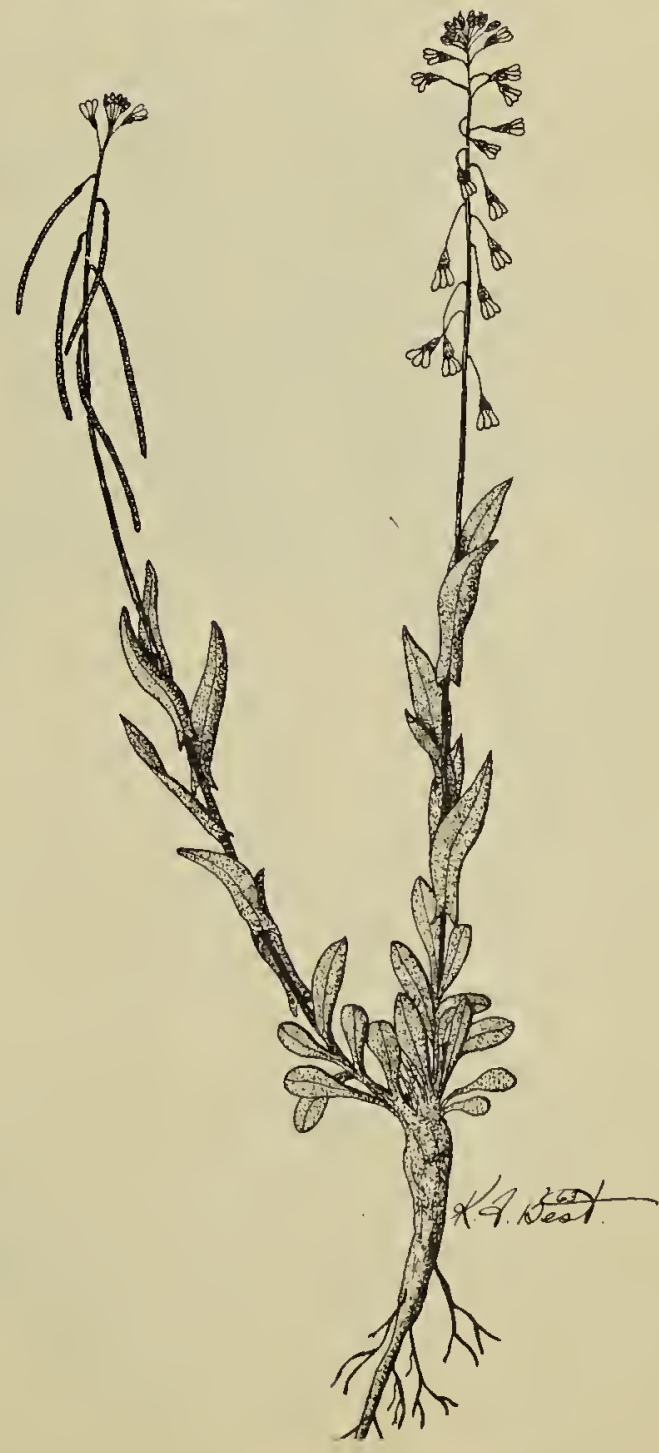

Reflexed Rock-Cress 